\title{
Thixoforming of Hypereutectic Al/Si Automotive Pistons
}

\author{
H. V. Atkinson ${ }^{1, \text { a }}$ and P. J. Ward ${ }^{2, b}$ \\ ${ }^{1}$ Department of Engineering, University of Leicester, University Rd., Leicester LE1 7RH, UK. \\ Formerly Department of Engineering Materials, University of Sheffield, Mappin St., Sheffield, S1 \\ 3JD, UK \\ ${ }^{2}$ Department of Engineering Materials, University of Sheffield, Mappin St., Sheffield, S1 3JD, UK.
}

\section{ahva2@le.ac.uk, ${ }^{\text {pp.ward@shef.ac.uk }}$}

Keywords: Thixoforming; hypereutectic aluminium/silicon alloys; pistons.

\begin{abstract}
For hypereutectic $\mathrm{Al} / \mathrm{Si}$ alloys, one of the advantages of thixoforming in comparison with casting routes is the relatively short processing times at high temperatures and hence limited coarsening of the Si phase. Coarse silicon particles give poor mechanical properties. Here two hypereutectic $\mathrm{Al} / \mathrm{Si}$ alloys (magneto-hydro-dynamically (MHD) stirred A390 from Pechiney and an extruded A390 alloy from Showa in Japan) have been thixoformed to form pistons. Opening up the die entrance to the full width of the crown made the flow into the die more uniform and helped to reduce the tendency for large pores to form due to swirling of the slurry. Die heating reduced cold shuts in the skirt (thin section) of the piston. Placing inserts into the die to make holes for the piston pins (i.e. having an obstacle in the thicker regions) evened up the flow between the thick and the thin regions in the die. Massive pores experienced in earlier shots were then eliminated. Placing ceramic material in the die entrance considerably reduced the shrinkage porosity in the crown. The use of the Showa alloy, where the globular semisolid microstructure is achieved by a solid state deformation route rather than MHD, gave reduced shrinkage porosity and eliminated macrosegregation of the eutectic and the silicon. Computer modeling has aided optimization of the die.
\end{abstract}

\section{Introduction}

Thixoforming is the shaping of metal alloys in the semi-solid state. The process was developed from studies into the flow properties of metallic alloy slurries at MIT (as reviewed in [1]). The process requires that the alloys be treated so that they possess a non-dendritic, spheroidal microstructure when reheated to between the solidus and liquidus. Spheroidal semi-solid alloys are thixotropic; when the billet is placed into the shot sleeve of a pressure die casting (or similar) machine, the shearing action during the shot causes the metal slurry to thin sufficiently for die filling to be achieved.

There are several methods of obtaining the spheroidal microstructure. Here, two different routes are used: electromagnetic (MHD) stirring (Pechiney A390 alloy) and casting followed by extrusion in the semi-solid state (Showa A390 alloy). This latter route involves recrystallisation and partial melting and is termed the RAP route [2].

Thixoforming has the potential to make possible the mass production of aluminium-high silicon pistons (initially $\sim 17 \% \mathrm{Si}$ by weight). This alloy is less dense and has a lower thermal expansion coefficient than gravity die cast pistons which are based on an alloy with the eutectic silicon content of $\sim 13 \%$. Gravity die casting of hypereutectic alloys is difficult because: the melt temperature has to be significantly higher than for a eutectic alloy $\left(\sim 750^{\circ} \mathrm{C}\right.$ vs. $\left.\sim 650^{\circ} \mathrm{C}\right)$ leading to die attrition and coarse silicon particles in the microstructure; there is a tendency for hypereutectic silicon to segregate especially in the thick sections of the castings; it is necessary to add a P refiner to the melt to ensure the Si assumes an equiaxed shape, rather than solidifying as plates - this effect can fade 
over time; extensive machining is required after casting e.g. $\sim 1-2 \mathrm{~mm}$ off the skirt thickness (a charge of $\sim 1 \mathrm{~kg}$ is required for a product with a final weight of $\sim 300 \mathrm{~g}$ ). Forging pistons also presents difficulties with high-silicon alloys because of the hardness of the material and difficulties with re-entrant surfaces. We have therefore investigated the possibility of thixoforming pistons from Al-high Si alloys. Some other reports on semisolid processing pistons are given in the literature [3-7].

\section{Experimental Method}

Thixoformer. The material was thixoformed on the University of Sheffield press [8]. This is a vertical upwards acting machine with induction heating (with a medium frequency generator) occurring in the press itself, which means that the cylindrical slugs of alloy do not require transfer to the press while semi-molten. (This method would not be employed in a commercial press because slug heating takes at least 6 minutes. A heating station would be used, programmed to deliver slugs in the right condition, as the press requires them. Commercial cycle times are typically 45s. For small pistons, several components can be made in one shot). The ram velocity profile during die filling, the final force and the time for which the force is applied are controlled using dedicated software.

Material. The material was A390 alloy (A117\% $\mathrm{Si} 5 \% \mathrm{Cu} 0.5 \% \mathrm{Mg}$ ) in two conditions: magnetohydrodynamically (MHD) stirred material from Pechiney (maximum Si particle size $\sim 60$ $\mu \mathrm{m}$ ); cast and extruded by Showa in Japan (Si particle size, made on laboratory equipment, $\sim 80 \mu \mathrm{m}$, smaller particle sizes are known to be available when the material is made on a commercial scale).

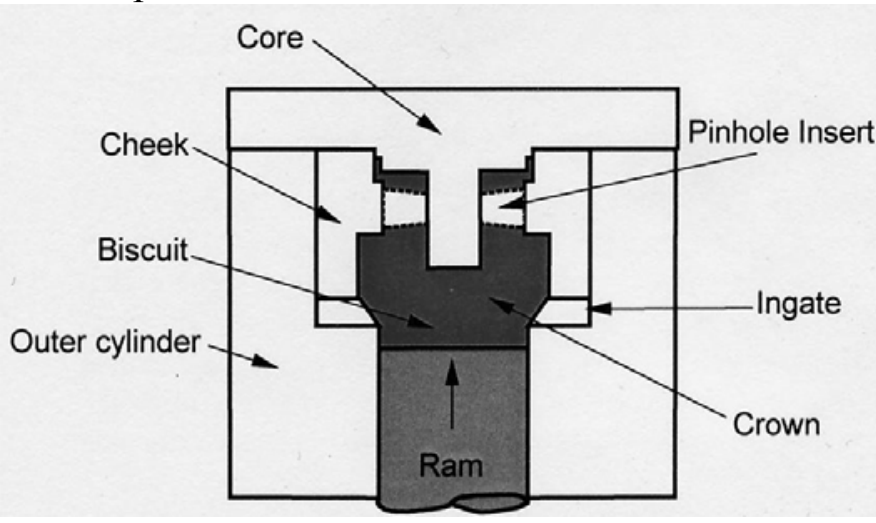

Fig. 1 Schematic diagram of the piston die. Vertical section through plane with piston pin holes. The metal slurry is shown as dark shading and the biscuit is removed after forming.

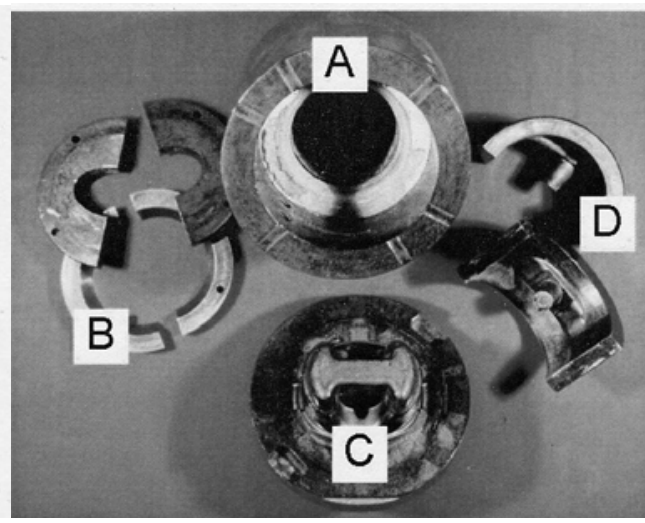

Fig. 2 Die components. $\mathrm{A}=$ outer cylinder, $\mathrm{B}=$ tapered ring gate and elliptical gate, $\mathrm{C}=$ core, $\mathrm{D}=$ cheeks.

Die. Fig. 1 shows a schematic of the die design and Fig. 2 a photograph. It was decided to thixoform into the crown end of the piston (rather than the side) as the die would be less complicated and costly and there would be less wastage due to runners and overflows. The die was manufactured from a high quality, high temperature tool steel and consisted of: 1) An outer cylinder, the lower portion of which was the die entrance, designed to be larger than the maximum size of billet required; 2) Two 'cheeks', machined to the shape of the outside of the piston - these slid into the upper part of the outer cylinder (later in the project, the cheeks were modified so that the gudgeon pin holes were formed in situ - this is shown in Fig. 1 by the dotted line inserts); 3) A disc (ingate) at the die entrance, to force the semi-solid metal slurry in the required direction during die filling - like the 'cheeks', this was split to ease removal of the component; 4) The die core, the top of which fitted closely into the 'cheeks' - this formed the internal surface of the piston and had the overflows machined into it. The die was heated with a band heater strapped onto the outer cylindrical surface. The temperature used was 300$370^{\circ} \mathrm{C}$. The hot die was insulated from the press with ceramic plates. After initial trials, some 
modifications were made: draught angles were added to the core to aid removal; the gating plates were bolted to the die 'cheeks', making them easier to release from the thixoformed piston; the die entrance diameter was enlarged from 65 to $70 \mathrm{~mm}$, increasing the gap between the entrance wall and the semi-solid slug; the ingate was redesigned into an elliptical shape so that it was wider and flared towards the component; redesign of the overflow wells facilitated removal of overflowed alloy.

Modelling. Die filling was modelled using the Flow3d computational fluid dynamics package (Flow Science Inc., USA). It was assumed the slurry was Newtonian (i.e. the viscosity was constant). This was known to be a gross approximation but at the time the thixotropic behaviour was not fully accounted for in Flow3d (it now is) and the Newtonian modelling did at least provide some guidance on die design.

\section{Results}

The first task was to find the minimum ram velocity at which the die could be filled with the new, elliptical entrance. The aim was to try and reduce the defects due to swirling and folding of the metal slurry, which were thought to originate from 'jetting' of material through the die entrance. The minimum velocity was found to be $0.3 \mathrm{~ms}^{-1}$ but the large pores in the gudgeon pin boss area were not eliminated. For the flow modeling, two values of the viscosity were then used, 1 Pas and 40 Pas. The low value showed swirling in the thick sections of the piston (Fig. 3), which probably leads to the defects found in practice. The higher value gave the die filling force in the model which was also obtained by measurement on the press and did not show the swirling. As noted above, the modeling is limited by its lack of accounting for thixotropy. Therefore, from a pragmatic point of view, for studying the swirling, the low viscosity was used but otherwise, for examining die design,

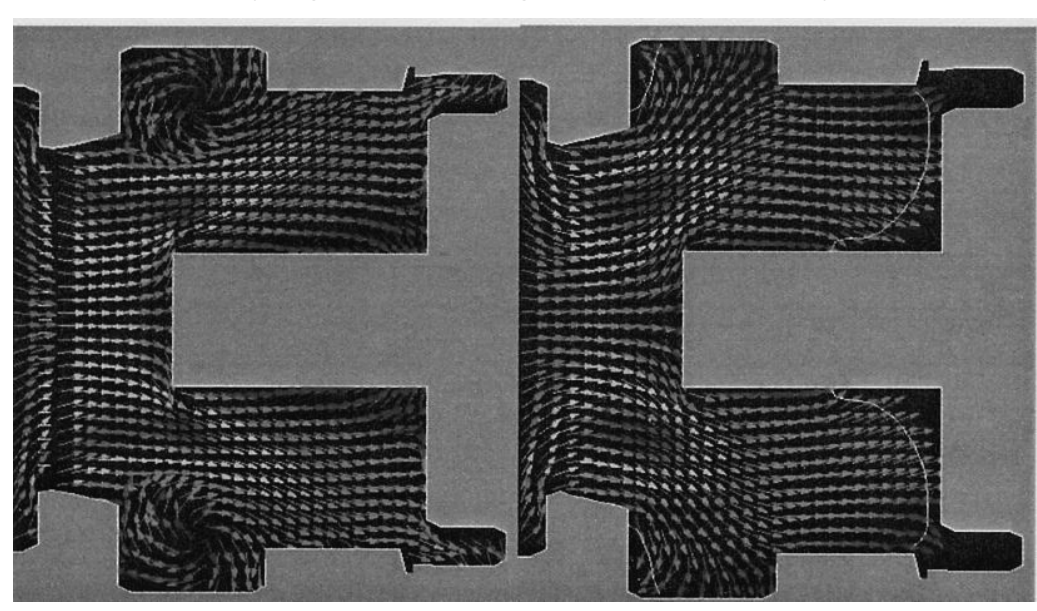

Fig. 3 Flow $3 \mathrm{~d}$ model showing swirling in thick sections of piston at 1 Pas (left) but not at 40 Pas (right). In all the modelling, the flow direction is left to right the higher viscosity was considered appropriate.

Ram speeds of $2.0 \mathrm{~ms}^{-1}$ and $0.3 \mathrm{~ms}^{-1}$ were used in the modeling. Die entrance designs were based on the elliptical ingate and the tapered ring shown in Figs. 1 and 2. The findings were as follows:

- Swirling of the alloy is worse at low viscosities and high ram speeds.

- At both viscosities, the gudgeon pin boss fills before the thin section in the plane at right angles to it. Creating an opening in the gate for this

boss (as with the elliptical ingate in the orientation used for thixoforming), without at the same time doing so for the thin section, makes this problem worse.

- Late filling of the thin section (i.e. the skirt) means that the two flow fronts meet in this part of the component, increasing the likelihood of cold shuts in this part of the piston.

- The best filling pattern was achieved with the tapered ring die entrance. However, even then the gudgeon pin boss filled before the thin section of the skirt.

Subsequent flow modeling looked at the following issues:

- Opening up the ingate opposite the thin section of the piston, with the aim of discouraging the slurry from taking the 'path of least resistance' into the gudgeon pin bosses.

- Examining the effect of gating the die from the side rather than from the crown end. 
- Adding a hole for the gudgeon pin, with side and crown gating systems.

The results suggested that improved die filling would be obtained by thixoforming the pinholes in

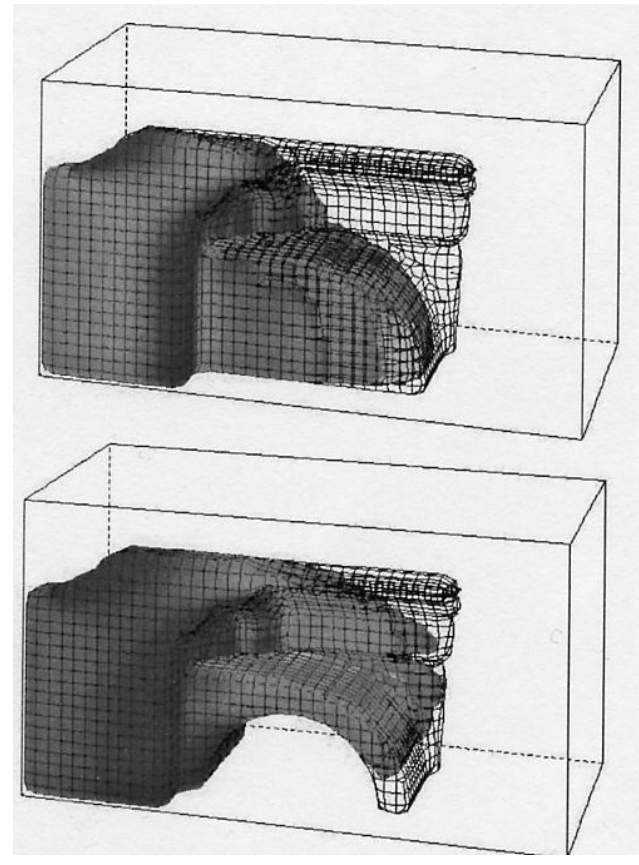

Fig. 4 Modelled filling sequence on $1 / 4$ piston showing how gudgeon pin boss fills later when pin hole is present (below). This makes the flow front more uniform. Greyscale colour represents pressure (dark is low)
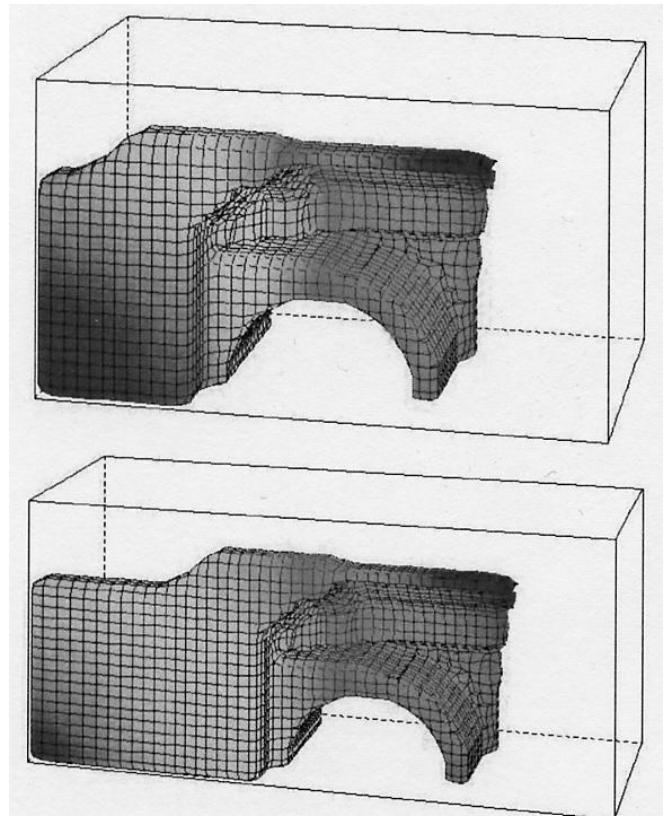

Fig. 5 Modelled effect of enlarging the slug. The last region to solidify (dark region on the left) moves from the crown (top) into the situ, with the fully open gate. The indications were that providing some constraint to flow in the gudgeon pin area would mean that this region did not fill much more quickly than the skirt; a more uniform flow front would ensue (Fig. 4). Furthermore, having to fill a thinner section in this area could reduce the swirling of the slurry. These changes caused a significant improvement in the product (made at this stage with the Pechiney alloy). The gross porosity in the gudgeon pin region was eliminated. Microstructurally, some regions showed a good, spheroidal microstructure but there were still several problems: shrinkage porosity between the crown and the core (this also occurs to a similar extent in gravity die cast pistons); segregation of liquid from the semisolid slurry; and areas where the aluminium spheroids appeared elongated and aligned in the slurry flow.

Measures to Improve the Microstructure in the Thixoformed Pistons. Several ways to reduce the crown shrinkage porosity were discussed. One possibility was increasing the slug volume, which should make the shrinkage porosity move down out of the crown region of the piston and into the biscuit. In practice, this did have the desired effect of driving some of the porosity further into the biscuit (and modelling showed this could happen - Fig. 5).

However, there were still large pores in the crown. In addition, filling was made more difficult, possibly due to the slug now being the same diameter as the die entrance and therefore freezing earlier. Several other possibilities were considered but it was not practical to implement them in this project: core cooling after completion of the shot; feeding from the side of the piston; using a ceramic material to replace the tapered metal ring at the die entrance.

There was also the issue of the $\mathrm{Si}$ segregation and the elongation or alignment of the Al spheroids mentioned above. A390 was obtained from Showa in the cast and extruded condition to compare with the behaviour of the Pechiney MHD alloy. It was known from a previous project that the material could be thixoformed [9]. In addition, it was decided to model the effects of a ceramic ingate. The results showed a more uniform temperature distribution than with the metal ingate. A ring to hold the ceramic moulding compound was machined, as was a former with the same $45^{\circ}$ profile as the metal ingate. The slug size was reduced so the biscuit did not extend further into the die entrance than this profiled ceramic ring. The biscuit would therefore not be cooled by the metal parts of the die. 
Thixoforming trials were performed with both the Pechiney and the Showa alloys. Using the ceramic die entrance resulted in a marked reduction in the shrinkage porosity in the crown (Fig.6).
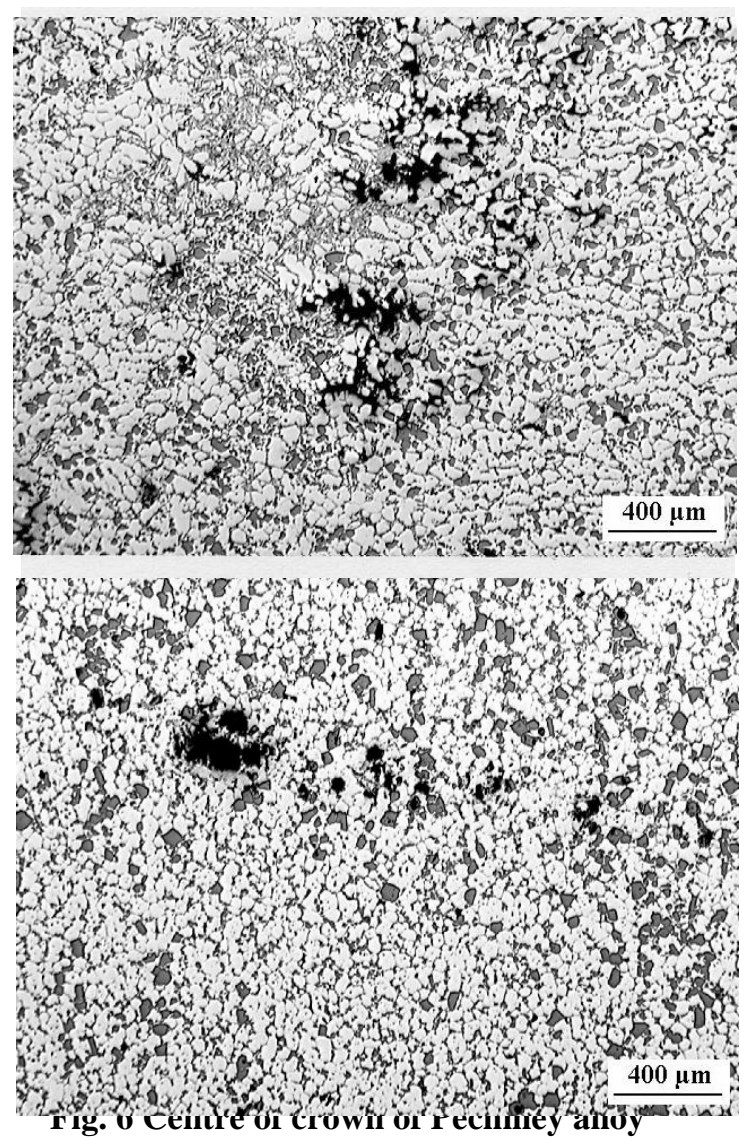

piston (top) and Showa alloy piston

(bottom), thixoformed with ceramic ingate.

Only one large pore was seen in the Showa

alloy. The Pechiney alloy had many pores.
The Pechiney alloy still had extensive segregation of eutectic and of silicon, but this was not evident in the Showa alloy, which also had even lower porosity.

It is not clear why there is such a problem with segregation in the Pechiney alloy. It appears to occur during the forming process. The nonspheroidal shape in places of the aluminium particles could cause liquid to be pushed through partially entangled Al particles (see Fig. 7 left). Even samples thixoformed under the optimal conditions occasionally show folds and large pores which could result from uneven flow of liquid-rich and liquid-poor regions. These tend to be nearer the extremities of the die, which are also richer in liquid. In parts of the die where the shear rates are high, elongated aluminium particles have been observed, aligned in the direction of the flow. The forces in die filling do not seem enough to actually elongate the particles during the process. It is possible that the uneven microstructure in the material causes the segregation of the particles with particularly high aspect ratio into certain regions of the die. Finally, it should be noted that the Pechiney alloy requires more liquid to be formed during reheating into the semi-solid state than for the Showa alloy. For this reason, the use of the ceramic die entrance did not totally eliminate shrinkage porosity below the crown surface.

Thixoforming the Final Batch of Pistons. In the final series of thixoformings, 22 shots were made with the Showa A390 alloy. The conditions were: ram speed $350 \mathrm{~mm} / \mathrm{s}$, load $70 \mathrm{kN}$, die temperature

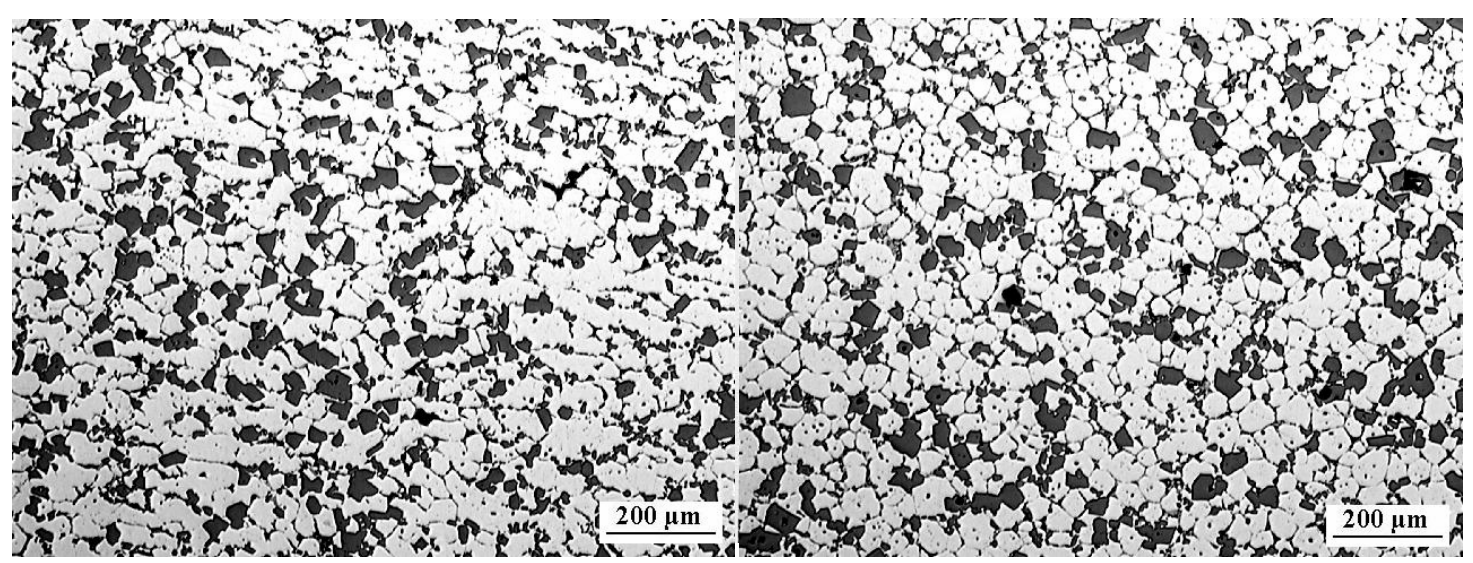

Fig. 7 Comparison of the aluminium grain shape in thixoformed Pechiney alloy (left) and Showa (right). In the latter, the microstructure is more spheroidal, probably resulting in smoother die filling and less segregation.

$370^{\circ} \mathrm{C}$. Six shots were radiographed. No internal porosity was found. Some examples of the thixoformed Showa pistons are shown in Fig. 8. 


\section{Summary}

Opening up the die entrance to the full width of the crown made the flow into the die more uniform and helped to reduce the tendency for large pores to form due to swirling of the slurry. Die heating reduced the tendency for cold shuts in the skirt (thin section). Placing inserts into the die to make holes for the piston pins evened up the flow between the thick and the thin regions in the die (i.e. having an obstacle in the thicker regions). The massive pores experienced in the earlier shots were eliminated. Placing a ceramic material in the die entrance considerably reduced the shrinkage porosity in the crown. Using the Showa alloy, made by mechanical deformation rather than MHD, reduced shrinkage porosity still further and eliminated macrosegregation of the eutectic liquid and the silicon.

Computer modeling has been of considerable assistance in examining the effects of potential changes to the die.

Acknowledgements The authors would like to thank Federal-Mogul (and in particular Joe Hunter) for their contribution to this project. The work reported here was part of a larger consortium project

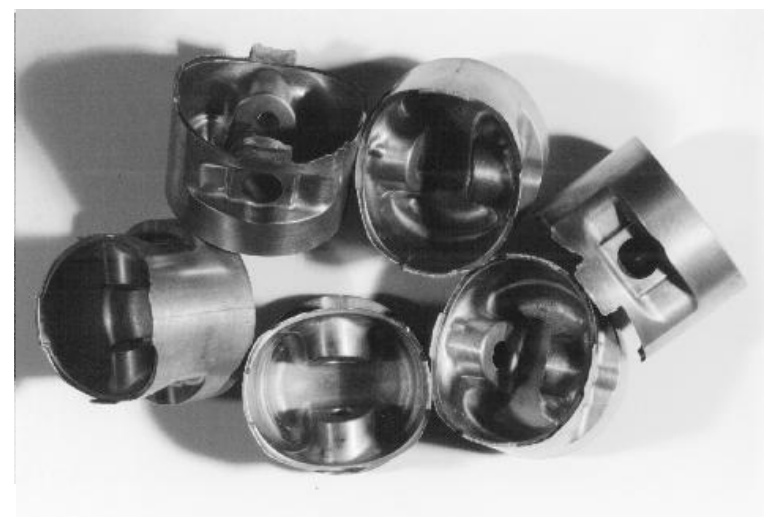

Fig. 8 Pistons thixoformed in the Showa A390 alloy. The biscuit has been machined off and the components washed. Otherwise, these are as-thixoformed. sponsored by the Engineering and Physical Sciences Research Council in the UK.

\section{References}

[1] M.C. Flemings: Metall. Trans. A., 22A (1991) p. 957.

[2] D.H. Kirkwood, C.M. Sellars, L.G. EliasBoyed: Thixotropic Materials. European Patent No. 0305375 B1; 28 October 1992.

[3] J.I. Choi, J.H Park, J.H. Kim, S.K. Kim, Y.H. Kim, J.H. Lee, Internat. J. of Advanced Manufacturing Technol., 32 (2007) p. 280.

[4] F. Kuthe, C. Afrath, A. Buehrig-Polaczek, Solid State Phenomena, 116-117 (2006) p.708.

[5] G. Govender, I. Ivanchev, N. Jahajeeah, R.

Bean, Solid State Phenomena, 116-117 (2006) p.501

[6] C.G. Kang, Y.P. Jeon, Proc. Inst. Mech. Eng. Part B - J.Engng. Manufacture, 217 (2003) 12651277.

[7] B. Bieri, P.J. Uggowitzer, T. Imwinkelried, J. Lagemann, J.-P. Gabathuler, M.O. Speidel, Proc. $5^{\text {th }}$ Internat. Conf. on Semi-Solid Processing of Alloys and Composites, eds. A.K. Bhasin, J.J. Moore, K.P. Young, S. Midson, Golden, Colorado, USA, 1998, Publ. Colorado School of Mines, p.531-537.

[8] P. Kapranos, D.H. Kirkwood, C.M. Sellars, Proc. $2^{\text {nd }}$ Internat. Conf. Processing of Semi-Solid Alloys and Composites, eds. S.B. Brown and M.C. Flemings, Massachusetts Institute of Technology, USA (1992) p. 119.

[9] P.J. Ward, H.V. Atkinson, P.R.G. Anderson, L.G. Elias, B.Garcia, L. Kahlen, J.M. RodriguezIbabe, Acta Metall. et Mater., 44 (1996) p.1717. 